\title{
Transdisciplinary Approach to Training Future Managers for Digital Education in Yakutia
}

\section{Enfoque transdisciplinario de la formación de futuros directivos para la educación digital en Yakutia}

\author{
Elizaveta Afanasyevna Barakhsanova* \\ M.K. Ammosov North-Eastern Federal University, Yakutsk, Russia \\ ORCID: https://orcid.org/0000-0003-3327-8773 \\ Anna Il'inichna Danilova \\ Churapchinsky State Institute of Physical Culture and Sports, Churapcha, Russia \\ ORCID: https://orcid.org/0000-0003-2054-2555 \\ Vladimir Polikarpovich Barakhsanov \\ M.K. Ammosov North-Eastern Federal University, Yakutsk, Russia \\ ORCID: https://orcid.org/0000-0001-7648-6922 \\ Alyona Vyacheslavovna Nikitina \\ Namsky Pedagogical College, Namtsy, Russia \\ ORCID: https://orcid.org/0000-0003-2751-0257

\section{Rimma Alekseevna Soloveva} \\ Arctic State Agrotechnological University, Yakutsk, Russia \\ ORCID: https://orcid.org/0000-0002-3616-7932
}

Received 07-10-20 Revised 08-25-20 Accepted 09-14-20 On line 09-15-20

*Correspondence

Email: ebarahsanova@yandex.ru
Cite as:

Barakhsanova E. A., Danilova, A. I., Barakhsanov, V. P., Nikitina, A. V., \& Soloveva, R. A. (2020). Transdisciplinary Approach to Training Future Managers for Digital Education in Yakutia. Propósitos y Representaciones, 8 (SPE3), e702. Doi: http://dx.doi.org/10.20511/pyr2020.v8nSPE3.702 


\section{Summary}

The article discusses the effectiveness of a transdisciplinary approach to training future managers of Yakut education. The study is based on the analysis of Russian and foreign theoretical positions on education management and organization of teaching programs for future education managers in the context of the digital education implementation. The authors examined the experience of managing and organizing the educational process at the NorthEastern Federal University (NEFU), Churapchinsky State Institute of Physical Culture and Sports (CSIPCS), and Yakut State Agricultural Academy (YSAA). One of the research methods was a survey of 250 students of these institutes, who are completing their Master's program in the following courses: Project Management in Education (NEFU), Innovation Processes in Education (NEFU), Corporate Digital Training (NEFU), Digital Training Management and Technology (NEFU), Vocational Education and Management in the Field of Physical Culture and Sports (CSIPCS), Management of the Crops Production Process in the Permafrost Zone (YSAA). The results of the study revealed the main features and trends of the educational management in a university. Practical significance of the work lies in the study and development of experience in introducing a transdisciplinary approach to training future managers of education.

Keywords: Transdisciplinary Approach; Education Manager; Digital Education.

\section{Resumen}

El artículo analiza la eficacia de un enfoque transdisciplinario para formar a los futuros gestores de la educación de los yakuts. El estudio se basa en el análisis de las posiciones teóricas rusas y extranjeras sobre la gestión de la educación y la organización de los programas de enseñanza para los futuros gestores de la educación en el contexto de la aplicación de la educación digital. Los autores examinaron la experiencia de gestión y organización del proceso educativo en la Universidad Federal del Nordeste (NEFU), el Instituto Estatal de Cultura Física y Deportes de Churapchinsky (CSIPCS) y la Academia Estatal de Agricultura de Yakut (YSAA). Uno de los métodos de investigación fue una encuesta a 250 estudiantes de estos institutos, que están completando su programa de maestría en los siguientes cursos: Gestión de Proyectos en Educación (NEFU), Procesos de Innovación en Educación (NEFU), Formación Digital Corporativa (NEFU), Gestión y Tecnología de la Formación Digital (NEFU), Formación Profesional y Gestión en el Campo de la Cultura Física y el Deporte (CSIPCS), Gestión del Proceso de Producción de Cultivos en la Zona de Permafrost (YSAA). Los resultados del estudio revelaron las principales características y tendencias de la gestión educativa en una universidad. La importancia práctica de la labor radica en el estudio y el desarrollo de la experiencia en la introducción de un enfoque transdisciplinario para la formación de futuros administradores de la educación.

Palabra clave: Enfoque transdisciplinario; Gerente de Educación; Educación Digital.

\section{Introduction}

At present, the system of higher professional education assumes the transdisciplinary nature of its organization with the aim of achieving the principle of fundamentality, high-quality education, versatility, universality of knowledge, and complex problems solving in the natureman-society system. The transdisciplinary approach is one of the most promising approaches to the development of pedagogical education in Yakutia.

Through the introduction of new federal state educational standards of higher education (FSES), we are moving away from subject-oriented educational programs in the form of a consistent study of individual scientific disciplines and mastering new conceptual approaches 
aimed at creating holistic systemic knowledge in the professional field. At this stage, the specifics of training education managers in the North-East of Russia provides the need to search for innovative approaches that will help preserve traditional lifestyle of the northern peoples, develop a holistic worldview, and form an ethnocultural competence. At the same time, these approaches should help master modern information and communication technologies and form progressive and rational thinking.

Regional education is transdisciplinary in nature, but, at this stage, there are no in-depth studies on the development of a theoretical basis for the organization of ethnocultural education, which should include both formal and informal education. In our opinion, such combination is possible with the introduction of the transdisciplinary approach in the process of ethnocultural education in conjunction with modern technologies necessary for training education managers in Yakutia.

Regional education in Yakutia forms a holistic worldview that combines traditional Northern mentality and modern technological thinking. Modern living conditions determine the current Yakut life specifics, which are provided for in the nature-man-society system.

Russian education system is rapidly improving and developing. Today, digital education is one of the main directions in the development of all spheres of human activity in the $21^{\text {st }}$ century. More often than not, such education is considered as the most effective type of training that allows to optimize educational process especially during economic recession (Vlasova et al., 2019; Aitbayeva et al., 2019).

In Russian educational institutions, digital education is carried out as part of educational, research, and pedagogic activities in accordance with FSES 3+ in the field of specialist training. Remote educational technologies, which include video and multimedia technologies, ensure the effectiveness of educational programs (Marchuk, 2013). At the same time, the regional education system of Yakutia is not very familiar with the nature and specifics of digital education.

The program for improving regional education in Russia includes the introduction of digital education, which should reflect the partnership of Russian universities in the field of pedagogical education. The Decree on Development of Digital Economy in the field of education also provides for the introduction of digital education. These tasks determined the purpose of the study - to identify current trends in the development of digital education in Yakutia based on the analysis of foreign and domestic studies in this field. Studying the experience of implementing digital education in the universities of Yakutia, we were able to identify the specifics of digital education and determine the essence of the students' digital dependence in educational activities and in practice (Vlasova et al., 2018).

The following research areas are in great demand today: further development of the Arctic civilization; the formation of innovative ways to acquire professional and vital competencies through vocational education; the development and testing of appropriate technologies necessary for implementing the transdisciplinary approach in the context of digital education in Yakutia.

\section{Literature Review}

In their works, foreign and domestic authors quite fully analyze the formation of the transdisciplinary approach in scientific research. Such Russian authors as Kiyaschenko and Moiseev (2009), Knyazeva (2011), Kolesnikova (2014), Mokiy and Mokiy (2014) analyze and develop theoretical views of Western "classics of transdisciplinarity," such as Judge (1994), Nicolescu (2006), and Moren (2013). 
Different authors interpret transdisciplinary approach in different ways, but we will give a general concept that characterizes transdisciplinarity as the basis for the formation of a fundamentally new approach to education.

An analysis of the sources makes it possible to single out the following ideas that form the core of the transdisciplinary approach:

- $\quad$ Complexity, multidimensionality, variability of the world;

- Recognition of the human consciousness' ability to reflect the complexity and multidimensionality of the world, which appears to him/her in theoretical and practical experience;

- $\quad$ Confirmation of the fundamental complementarity of the cognition forms and the need to combine the meanings that lie outside the boundaries of specific disciplines and go beyond the interdisciplinary and purely scientific cognition forms;

- Striving to identify and solve the most complex socially important life problems, which by their nature cannot be comprehended within the framework of one scientific discipline;

- Recognition of the right to general public discussion of socially important scientific information and its scope.

Therefore, the transdisciplinary approach provides educational science with the ability to fill in the methodological gaps in the description of the educational reality that are inherent in its categorical apparatus (Kolesnikova, 2014). Education, as a continuous process, and educational science reflect complex legal, economic, social, and cultural aspects. At the same time, some participants of the educational process don't always accept the proposed educational programs, methods of communication, etc. To accept such innovations, the teacher must have a holistic perception and professional understanding of the human nature.

At the present stage, interdisciplinary integration is impossible without the ITdevelopment of education. Among other things, such development involves the creation of interdisciplinary online educational and methodological complexes, which include the following:

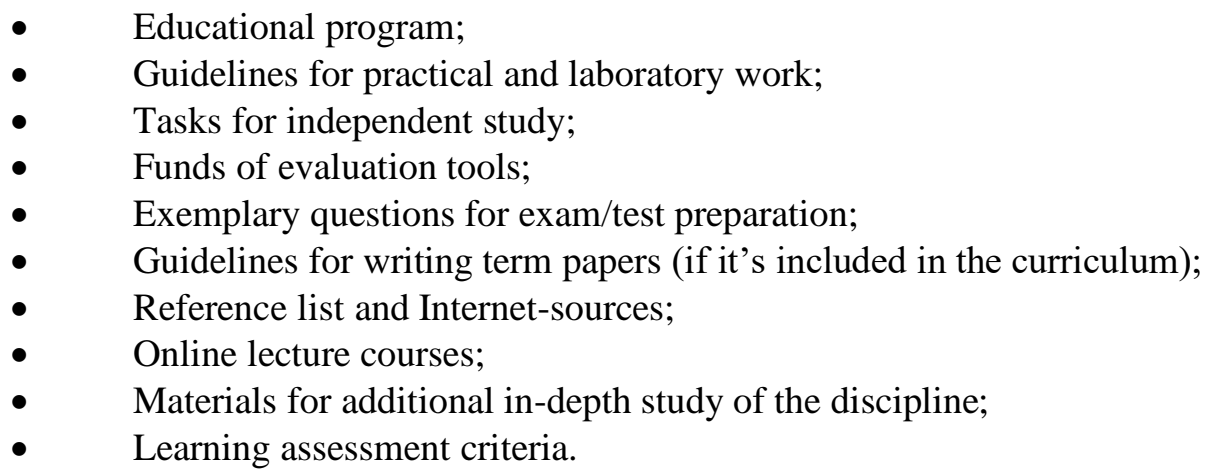

We believe that digital education should be introduced into the training programs of the future education managers, which is carried out on the basis of the transdisciplinary approach (Barakhsanova, 2019). The existing subject-oriented system of vocational education is focused on independent and limited educational disciplines, and this fact prevents the formation and development of intersubjective communications, which are the most important imperative for the training of a modern specialist. This explains the need to adopt the transdisciplinary approach in educational organizations in a digital educational environment. Interdisciplinary communications are formed through the introduction of integrated courses that create an integral type of learning (Goncharova, 2017; Radif \& Mohammed, 2019; Gharawi et al., 2020). 
One of the main missions of pedagogical universities is to provide the education sector with personnel who are ready to make managerial decisions in the context of uncertainty and modernization of the education system. In the context of the educational process organization, transdisciplinarity is a way to develop educational programs, to change the relations between the subjects of the educational process, to gradually revise the possibilities that students have in the educational space (Kotova, 2016).

Foreign researchers have accumulated a wealth of experience in introducing and developing digital education in various aspects of educational activities.

According to Belisle and Rosado (2006), literacy not only provides methods and tools for working with texts and numbers in a specific cultural and ideological context but also enriches and transforms the possibilities of the human mind. This intellectual enrichment happens whenever humanity gains new cognitive tools — such as writing — or technical tools that became available with the advent of digital technology. Belshaw (2012) identifies the following eight components of digital literacy development: cultural, cognitive, constructive, communicative, confidential, creative, critical, and collective.

Much attention was paid to foreign studies on the relationship between information and communication technologies and cultural values. The relationship between technology and cultural values was defined by Salehan et al. (2018); in their work, Woods and Rosenberg (2016) described educational tools and thinking outside the box; Kaplan and Haenlein (2016) examined the attitudes of social media users towards digital revolution and the development of higher education.

The search for ways to solve pedagogical problems has always involved the use of different approaches that already have a fundamental foundation in pedagogical science in the form of various studies conducted by different authors. Today, the transdisciplinary approach is one of the most studied approaches in the global scientific community. Mokiy (2011) believes that its implementation is not sufficiently understood by the Russian scientific community and is characterized by a very low level of acceptance in Russian universities. Meanwhile, in many other countries, this approach is being studied in special centers where grant research and projects are funded and conducted (Mokiy, 2011). The transdisciplinary approach is based on the theory of holism, but the understanding of its field is much broader than that of the previous approaches.

Science is becoming less fundamental and experimental and more pragmatic, more socially and practice oriented; it goes beyond its own scientific categories, concepts, and meanings. Therefore, global trends in the nature of science dictate the need to find ways to rethink the existing social problems in the framework of existing scientific disciplines.

In this aspect, we find the use of the transdisciplinary approach in the study of the pedagogical science problems absolutely reasonable and objective.

\section{Materials and Methods}

The study was conducted by a team of authors in the period from 2015 to 2019. The collaborative nature of the study allowed us to effectively use existing professional and scientific assets, study the problem from different angles and consider various proposals for its solution, organize cooperative work of the pedagogical teams in order to adapt to innovative work, and, therefore, remain dynamic and flexible professionals.

The use of the transdisciplinary approach allowed the development of two Master's degree programs: Corporate e-Learning and Project Management in Education, which provide a comprehensive approach to training and involve digital learning. These courses are designed to 
train specialists in the field of project management in education, as well as administrative and executive employees of various education governing bodies.

The transdisciplinary approach involves the transfer of integral blocks of information that give an overall picture of the world, rather than that of a single phenomenon or problem (Panina et al., 2016). According to this principle, the following educational modules have been developed at NEFU: Philosophical and Methodological Foundations of Pedagogical Research, Project Management in the Context of the Digital Education Implementation, Project Development in Education, and Practical Work that includes Research Work.

Intramodular relations between disciplines form an interdisciplinary synthesis of knowledge, which illustrates the profound changes in the methodological foundations of modern science, in the philosophical worldview, and in the style of scientific thinking. For example, the training module Philosophical and Methodological Foundations of Pedagogical Research includes the study of philosophy, science, education, modern scientific and educational problems, as well as the methodology of pedagogical research. The disciplines of this module are based on each other and support each other.

Considering the professional skills of the university teaching staff on the basis of the transdisciplinary approach, we focused on the methodological culture and creative potential. Based on this principle, the following original courses were developed: Expert Project Management in Education, Strategic Development of Educational Systems on the Basis of Project Management, Scientific and Methodological Work Development in the Digital Educational Environment, Digital and Informational Educational Environment in the Work of a Modern Teacher of Higher and Secondary Special Education, Career Guidance Modeling in Regional Educational Environment.

We believe that professional skills of specialists with a master's degree are not limited to a specific place of work. Such specialists may be in demand in state and municipal government organizations, particularly in state and regional departments and committees of education, as well as in scientific committees.

The contradictions between the following circumstances were identified during the analysis of the literature used in the study: the objective need of modern educational organizations for specialists with a developed managerial and pedagogical culture and the real practice of training future education managers; the need to ensure the competitiveness of a specialist in the field of educational management and an insufficient training mechanism.

A survey was conducted in order to determine whether students have any ideas about the work of education manager and assess the level of their professional, personal, and special competencies. We interviewed 250 students of three educational organizations, who are completing their Master's program in the following courses:

\section{- $\quad$ Project Management in Education (NEFU) \\ - Innovation Processes in Education (NEFU) \\ - $\quad$ Corporate Digital Training (NEFU) \\ - $\quad$ Digital Training Management and Technology (NEFU) Sports (CSIPCS) \\ Vocational Education and Management in the Field of Physical Culture and \\ - $\quad$ Management of the Crops Production Process in the Permafrost Zone (YSAA)}

The results of the survey showed that $48 \%$ of students in their first and second years of study do not have any work experience, which indicates that they have almost no idea about the specifics of their future professional activities. $22 \%$ of students have working experience of less 
than 1 year; $16 \%$ have $1-5$ years of experience, $13 \%$ have $5-10$ years of experience, and $8 \%$ of students - more than 10 years.

We also asked students what they consider to be their strengths and weaknesses, what competencies they consider the most necessary for the effective work of a modern manager. During the survey, students were able to put forward their proposals to improve their professional competencies in the context of digital education.

When asked about managerial competencies, $72 \%$ of students answered that the most important is the ability to plan and organize work activities and the ability to make decisions; $45 \%$ of students believe that effective work requires leadership skills; and $16 \%$ of students find necessary the skills of delegation. In our opinion, this is due to the lack of managerial practice, where the distribution of functions, delegation skills, the ability to determine one's own leadership potential are necessary.

While assessing communicative competencies, students pointed out persuasion skills $(82 \%)$, contact skills $(84 \%)$, flexibility $(78 \%)$. Only $56 \%$ of respondents think that teamwork and listening skills are necessary competencies of a successful manager in education. We believe that this is due to the lack of work experience in real teams and the insufficient development of communicative skills. When assessing personal competencies, students marked responsibility (92\%), desire for self-improvement (72\%), and resistance to stress $(62 \%)$ as highly necessary competencies of managers in education. Only $35 \%$ of respondents considered creativity as an obligatory competency of an educator. Among the special competencies, students marked as necessary only the ability to apply knowledge in practice (67\%). Students found all other competences as optional. Perhaps this is due to lack of knowledge of the specific place of future employment and lack of practical experience.

When describing their strengths, students pointed out sociability, creative approach to problem solving, high professional motivation, and the ability to plan and control their work, while the lack of practical work experience and inability to apply theory in practice were considered as weaknesses.

The students made the following proposals for improvement of professional competences and change in the educational process: increase the number of hours for internship, organize internships with the option of subsequent employment, increase the amount of practicum classes, reduce the amount of lecture classes, organize practicum classes with the aim to develop specific skills and competences. There were also suggestions to organize meetings with successful managers of educational institutions for experience exchange on a regular basis.

\section{Results and Discussion}

Training a specialist in the field of project management in education is a complex process, the interpretation of which should be covered from various points of view. For this reason, we have developed an educational module Project Management in the Context of Education Modernization, which includes the following disciplines: Strategic Development of Educational Systems on the Basis of Project Management, Expert Project Management in Education, Legal Basis of Project Management, New Educational Technologies, and Quality Management in Education.

The purpose of this module is to develop common skills in cognitive, evaluative, communicative, and creative activities on the basis of a competency-building approach and the knowledge gained in the process of studying pedagogy, psychology, and other social sciences. 
The choice of the proposed disciplines is consistent with the order of the employer, which was reflected in the work description for the master's degree holders in the field of project management in education.

In our opinion, it is expressed through the following requirements: educational process;

The ability to design an educational environment that ensures the quality of the

The study of the state and potential of the managed system and its macro- and microenvironment by using methods of strategic and operational analysis;

The study and organization of the management process using management technologies that correspond to the general and specific laws, under which the managed system develops, and evaluation of the results;

- $\quad$ Taking advantage of the available environmental capabilities of a managed system and designing ways to enrich and develop it in order to ensure management quality.

It is important for the future manager in education to develop personal and professional qualities. He/she should have communicative and leadership qualities, i.e. be able to unite the staff, establish business contacts, be approachable and open for dialogue and discussion, aim for mutual agreement with the staff. Such a specialist should also be able to organize optimal interaction within the work group and stimulate the activity of employees, urge them to develop their professional qualities.

These personal and professional qualities will help the manager to build a conflict-free working relationship, unite team members, and effectively manage staff. To develop these competencies, students - with the help of a tutor — create individual educational routes for practical training.

Interdisciplinary integration is carried out on the basis of cyclic, interdisciplinary, and intradisciplinary relations and represents a logically complete structure of multidisciplinary knowledge. Such integration supplements the content of one discipline with knowledge from another, unites them, and provides not narrowly disciplinary but activity-based training, which develops professionally important personal skills and qualities (Vishnyakova, 2007).

The following pedagogical, general educational and psychological conditions contribute to the formation of scientific concepts on the basis of interdisciplinarity:

1. Time-coordinated study of individual academic disciplines, in which each of them is based on a previous conceptual base and prepares students for successful mastery of the subsequent discipline.

2. Continuity in the development of concepts: the concepts that are common to a number of disciplines must be continuously developed throughout the course, filled with new content, enriched with new connections.

3. Unity in the interpretation of general scientific concepts.

The implementation of these functions allows for the versatile education, which is why the educational function is an integrating function.

With the existing subject-block system of education, integrated courses may become the most acceptable way of developing an integral type of cognition. The methods for developing and constructing such courses are different and depend on the goals, the degree to which integrable disciplines are included in the general problem field, the nature of interdisciplinary connections (direct or indirect), and, finally, on the developers' individuality.

The development of a module has the following mandatory requirements: 
- $\quad$ Time-coordinated study of individual academic disciplines, in which each of them is based on a previous conceptual base and creates conditions for the successful mastering of concepts on the basis of interdisciplinarity;

- $\quad$ Continuity in the development of concepts that provides for their consistent filling with new content and enrichment with new connections;

- Unity in the interpretation of general scientific concepts;

- Consistent approach to the organization of educational process in all components of the module.

The system of developed disciplines corresponds to the principle of the initial modularity of the course. The material in such a system is clearly structured and its presentation is dynamic; students have the ability to gain relevant knowledge and use a variety of didactic tools, e.g., integrated lectures, project development, and others.

The problem is that the future specialist must have the skills and professional mobility to quickly respond to constant changes that occur in practice and scientific activities.

Therefore, interdisciplinary integration is one of the most important areas for improving education in a modern university.

\section{Conclusion}

The process of vocational training is considered as a holistic educational system. The center of this system is the student's personality, which in turn is also a complex self-organizing system.

In reality, systems that consist of several complex components are implemented in conditions of diversity, fragmentation, randomness, spontaneity, and unpredictability.

The transdisciplinary approach can be implemented using the following mechanisms:

- $\quad$ Future teachers of the Northeast Russia should be trained with regard to the specifics of the national-regional education system, physiological and mental development of indigenous children, and the traditional lifestyle of indigenous peoples;

- Modular training programs for future teachers and educators should be developed and widely distributed; they should be focused on the integration between research and educational activities, internationalization of education related to migration processes in Siberia and the Far East, practical implementation of the network educational consortium model;

- Due to the territorial features of the region, particularly in the North, it is necessary to use distance learning technologies that are aimed at developing interdisciplinary competencies and mastering the scientific and traditional lifestyle foundations of the indigenous peoples of the Northeast Russia.

\section{References}

Aitbayeva, B. M., Maulenova, A. M., Akhmetzhanova, Z. B., Kenzhebekova, Z. A., \& Rakhimbayeva, B. O. (2019). Sustainable development of educational institutions in the context of the introduction of elements of distance education in the learning process. Periódico Tchê Química, 16(33), 404-422.

Barakhsanova, E. A. (2019). Transdisciplinary approach to the implementation of Master's network university programs. Materials of the 3rd International Scientific Conference "Informatization of Education and E-Learning Methodology", 31-36. Krasnoyarsk: Siberian Federal University, Institute of Space and Information Technologies. 
Belisle, C., \& Rosado, E. (2006). Analysing digital literacy frameworks. A European Framework for Digital Literacy. [https://pdfs.semanticscholar.org/5db7/5a1fa1d1998f6638426aca002191df2d21b3.pdf?_ $\mathrm{ga}=2.200424494 .1499295010 .1595848776-1335596136.1560356921]$ [Accessed on 13 March, 2020].

Belshaw, D. (2012). What is 'digital literacy'? A pragmatic investigation. Doctoral Thesis, Durham University, Durham.

Gharawi, M. A., Bidin, A., \& Choo, K. A. (2020). Malaysian learners' preferences-based profile model towards adaptive massive open online courses. Journal of Southwest Jiaotong University, 55(1). doi:10.35741/issn.0258-2724.55.1.51

Goncharova, S. V. (2017). Possibilities of using E-learning technologies in the "Information Technologies in Management" discipline. News of the Baltic State Academy of the Fishing Fleet: Psychological and Pedagogical Sciences, 2(40), 74-77.

Judge, A. (1994). Conference paper. 1st World Congress of Transdisciplinarity. Brussels: Union of International Associations.

Kaplan, A. M., \& Haenlein, M. (2016). Higher education and the digital revolution: About MOOCs, SPOCs, social media, and the Cookie Monster. Business Horizons, 59(4), 441450.

Kiyaschenko, L. Y., \& Moiseev, V. I. (2009). Philosophy of transdisciplinarity. Moscow: Russian Academy of Sciences.

Knyazeva, E. N. (2011). Transdisciplinary research strategies. Tomsk State Pedagogical University Bulletin, 10, 193-201.

Kolesnikova, I. A. (2014). Transdisciplinary strategy of studying continuing education. Continuing Education: The XXI Century, 4(8). doi:10.15393/j5.art.2014.2642

Kotova, N. A. (2016). Transformation of ideas about the university educational environment in the context of different methodological approaches. Tambov University Bulletin. Social Science Series, 21(1(153)), 33-45.

Marchuk, N. Y. (2013). Psychological and pedagogical features of distance learning. Pedagogical Education in Russia, 4, 78-85.

Mokiy, M. S., \& Mokiy, V. S. (2014). Transdisciplinarity in higher education: Expert assessments, problems, and practical solutions. Modern Problems of Science and Education, 5. [www.science-education.ru/119-14526] [Accessed on 13 March, 2020].

Mokiy, V. S. (2011). Transdisciplinary philosophy of the noumenal world. Nalchik: Institute of Transdisciplinary Technologies.

Moren, E. (2013). Method. The nature of nature. Moscow: Kanon, RSDP Rehabilitation.

Nicolescu, B. (2006). Transdisciplinarity - past, present and future. In B. Haverkort \& C. Reijntjes (Eds.), Moving worldviews - Reshaping sciences, policies and practices for endogenous sustainable development (pp. 142-166). Holland: Compas Editions.

Panina, S., Tulasynova, N., \& Gotovtseva, N. (2016, August). Developing value paradigm of rising educators at university. 3rd International Scientific Conferences on Social Sciences \& Arts SGEM, 187-194.

Radif, M., \& Mohammed, N. A. (2019). Computer science teacher's perception and needs towards E-learning in Iraq. Journal of Southwest Jiaotong University, 54(5). doi:10.35741/issn.0258-2724.54.5.42

Salehan, M., Kim, D. J., \& Lee, J. N. (2018). Are there any relationships between technology and cultural values? A country-level trend study of the association between information communication technology and cultural values. Information \& Management, 55, 725745 .

Vishnyakova, E. G. (2007). Interdisciplinary network educational and methodological complex as a means of increasing the effectiveness of university training. Candidate Thesis, Volgograd.

Vlasova, E. Z., Barakhasanova, E. A., Goncharova, S., Aksyutin, P., Kuzin, Z. S., \& Prokopyev, M. S. (2018). Effective adaptive training of students in Russian pedagogical universities to use E-learning technologies. Espacios, 39(23), 10. 
Vlasova, E. Z., Goncharova, S. V., Barakhsanova, E. A., Karpova, N. A., \& Iljina, T. S. (2019). Artificial intelligence for effective professional training of teachers in the Russian Federation. Espacios, 40(22), 9.

Woods, M., \& Rosenberg, M. E. (2016). Educational tools: Thinking outside the box. Clinical Journal of the American Society of Nephrology, 11(3), 518-526. 